\title{
DE DISCENTE A DOCENTE: RELATO DE EXPERIÊNCIA NO DANÇAR FAZ BEM
}

A.R. Gomes ${ }^{\mathbf{1}}$ \& L. M. Cortonesi ${ }^{2}$
Araduanda em Administração pela Universidade Federal do Ceará (UFC); graduada em Estilismo e Moda pela UFC. E-mail:
alinearg@ gmail.com; ${ }^{2}$ Doutor em Educação Brasileira pela Universidade Federal do Ceará e Docente Adjunto IV da UFC. E-mail:
lemasuda@ @otmail.com
Artigo submetido em setembro/2018

\section{RESUMO}

Fundado em 2001, o Dançar Faz Bem (DFB) é um projeto de extensão do curso de Educação Física da Universidade Federal do Ceará (UFC) que oferece gratuitamente aulas de dança de salão à comunidade, promove práticas, além de realizar apresentações em diversos eventos na cidade divulgando esta modalidade. O presente trabalho consiste em relatar a experiência enquanto aluna e posteriormente membro atuante na equipe pedagógica do projeto, apresentando as impressões e repercussões do DFB sob a visão discente e docente. Nesse intuito, foram analisados os registros documental e etnográfico e buscou-se descrever as etapas de planejamento, organização e realização das atividades da equipe pedagógica no ciclo de um semestre, período da turma regular. A experiência se revelou bastante desafiadora e enriquecedora, permitindo compreender o papel do DFB como agente transformador de realidades, tanto de alunos, como de professores, bem como seu impacto no cenário da dança de salão da cidade.

PALAVRAS-CHAVE: Dança de Salão. Ensino. Educação. Arte.

\section{FROM STUDENT TO TEACHER: EXPERIENCE REPORT ON THE DANÇAR FAZ BEM}

\begin{abstract}
Founded in 2001, Dançar Faz Bem (DFB) is an extension project of the Physical Education course of the Universidade Federal do Ceará (UFC), which offers free dance classes to the community, promotes practices and also performs presentations at events in the city announcing this modality. The present work consists in reporting the experience as a student and later acting member in the pedagogical team of the project, presenting impressions and repercussions of the DFB under the student and teacher vision. In this
\end{abstract}

purpose, the documentary and ethnographic records were analyzed and it was described the steps of planning, organizing and carrying out the activities of the pedagogical team in one semester. The experience proved to be challenging and enriching, making it possible to understand the role of the DFB as a transforming agent of both pupils and teachers realities, as well as its impact on the city's ballroom dancing scene.

KEYWORDS: Ballroom Dancing. Teaching. Education. Art.

\section{INTRODUÇÃO}

O Dançar Faz Bem (DFB) é um projeto de extensão fundado em 2001 pelo aluno Walberto Gomes Filho do curso de Educação Física da Universidade Federal do Ceará (UFC). Segundo Pereira (2011), Walberto tinha o propósito de divulgar a dança de salão como uma atividade física importante não somente para o condicionamento físico do ser humano, mas 
também como uma forma de promoção da sociabilidade entre seus praticantes.

Atualmente, dentre as suas atividades, o Dançar Faz Bem oferece gratuitamente aulas de dança de salão à comunidade acadêmica e não-acadêmica, promove práticas, aulões de divulgação, oficinas de dança, cursos de férias, além de realizar apresentações artísticas em diversos eventos na cidade divulgando esta modalidade (PROJETO DANÇAR FAZ BEM UFC, 2018).

O DFB, conforme o Manual do Aluno Dançar Faz Bem (2018), tem como missão disseminar o amor pela dança de salão de forma respeitosa, lúdica e cooperativa, proporcionando bem-estar e laços de amizade. Sua visão consiste em popularizar a prática de dança de salão na comunidade de Fortaleza e seus valores se baseiam em cinco princípios:

\footnotetext{
1) Dinamismo - acreditamos que a alegria é a energia transformadora que a dança pode proporcionar;

2) Amizade - o companheirismo é fruto dos relacionamentos estabelecidos na dança;

3) Naturalidade - a simplicidade e a espontaneidade são os elementos norteadores do aprendizado na dança;

4) Cordialidade - consideramos que a parceria na dança envolve gentileza;

5) Ética - buscamos agir com transparência e respeito mútuo. (MANUAL DO ALUNO DANÇAR FAZ BEM, 2018, p.1).
}

A prática do dançar nesse projeto é entendida como uma atividade que ultrapassa o limite do aprendizado de passos de dança de salão. São trabalhadas habilidades sociais e incutida uma filosofia de respeito e boa convivência na interação entre os casais de dança onde se acredita que se refletirá na conduta dos participantes do Dançar Faz Bem junto à sociedade (UFCTV, 2018).

A atividade docente no projeto é realizada mediante permanente capacitação da equipe de monitores para que posteriormente estejam habilitados a ministrar aulas. Faz parte dessa ação a recepção de alunos de outros cursos no intuito de acompanharem o processo de ensinoaprendizagem do DFB através de estágios supervisionados e/ou trabalhos de pesquisa, colaborando, dessa forma, para o desenvolvimento da equipe pedagógica como educadores.

No decorrer de sua trajetória de 17 anos, o Projeto Dançar Faz Bem beneficiou cerca de 3500 alunos, promovendo uma mudança no cenário da dança de salão da cidade, que outrora se restringia a uma pequena parcela da sociedade focada no público de idade avançada e na atualidade conta com a forte adesão do público jovem e com escolas de dança gerenciadas por professores que fizeram parte da equipe pedagógica deste projeto de extensão.

Diante do contexto apresentado, esta pesquisa visa relatar a experiência, tanto como aluna, quanto como voluntária no exercício da docência no Dançar Faz Bem, de modo a 
externar as impressões e repercussões sob os dois pontos de vista, bem como descrever as atividades pertinentes ao ciclo semestral de turmas regulares desse projeto.

\section{RELATO DE EXPERIÊNCIA}

O relato de experiência, gênero textual evidenciado por Eulálio, Nascimento, e Albuquerque (2013) como um escrito que desempenha a função social de explanar uma vivência, é trabalhado na presente pesquisa com o propósito de compartilhar as experiências obtidas na atuação como discente e docente no projeto de extensão Dançar Faz Bem.

\subsection{Sob o olhar discente}

Era período de férias de julho de 2007 quando se ouviu falar das inscrições para o semestre 2007.2 do Projeto Dançar Faz Bem, época na qual as aulas ainda ocorriam na sala de artes do bloco da Faculdade de Educação (FACED) localizado no Centro de Humanidades I, Campus do Benfica, da Universidade Federal do Ceará. Era necessário chegar muito cedo, ainda pela manhã em um dia de sábado, para conseguir vaga na turma regular do semestre, cuja inscrição ocorreria somente no início da tarde. Apenas as trinta primeiras damas e os trinta primeiros cavalheiros da fila teriam acesso à nova turma de iniciantes do semestre e, como a procura pelas aulas do projeto nessa época já era intensa, muitos que compareciam no dia de inscrição não encontravam vagas disponíveis.

Entre o horário de chegada à fila de espera, por volta de $7 \mathrm{~h}$ da manhã, até o horário da inscrição, programada para as $14 \mathrm{~h}$, tinha-se a oportunidade de se familiarizar com quem também aguardava a hora tão esperada, além de presenciar tumultos de quem chegava mais tarde e percebia que não conseguiria a vaga, mas mesmo assim permanecia na fila com a expectativa de participação no aulão de divulgação das modalidades de dança de salão ofertadas no semestre. Nesse dia a fila chegou a ter mais de cem pessoas, ávidas pelo ingresso no mundo da dança de salão.

Passado o momento de inscrição, partiu-se para a explanação do histórico do projeto de extensão, apresentação da equipe pedagógica que compunha o projeto na época e deu-se início ao aulão, com demonstrações dos ritmos ofertados na turma de iniciantes do semestre 2007.2: Forró, Salsa, Bolero, Samba e Soltinho. Ao final do aulão ministrado, era nítido o 
encantamento despertado nos novos ingressantes da turma iniciante, bem como o aumento do desejo de participação daqueles que não conseguiram uma vaga na turma.

A procura pelas aulas de dança se deu por dois propósitos, o primeiro deles, pelo encantamento com a dança de salão, já o segundo motivo foi visando combater algo que prejudicava bastante a vida acadêmica e profissional: a timidez. Em meio às dificuldades iniciais comuns de alunos iniciantes enfrentadas para memorizar todas as movimentações passadas nas aulas, teve-se a ideia, por parte de alguns alunos, da realização de encontros extra classe nas suas casas com o intuito de praticar o que era visto em sala de aula, bem como estudar novas movimentações. Essa iniciativa, que teve início com um grupo de três alunos do Dançar Faz Bem dentre os quais a voluntária autora do projeto fez parte, mais tarde passou a constituir como mais um meio de sociabilidade entre os alunos e também de quem desconhecia o projeto, pois teve a forte adesão dos alunos, amigos dos alunos, ex-alunos do projeto de extensão, além de contar com o apoio e estímulo dos professores do DFB.

Passados dois anos desde o início da participação nas aulas do projeto, houve um hiato de seis anos com retorno em 2016, novamente como aluna do Dançar Faz Bem, ocasião na qual simultaneamente abriram um curso de formação para monitores e surgiu o convite para integrar a equipe pedagógica do DFB, função que foi iniciada em 2017 e ocorre na sala de lutas do Instituto de Educação Física e Esportes (IEFES), situada no Campus do Pici, da UFC.

\subsection{Na visão docente}

A atuação da equipe pedagógica no ciclo de um semestre, período de cada turma regular do Dançar Faz Bem, obedece as etapas de planejamento, organização e realização das atividades necessárias à concretização da turma semestral. Cada etapa é permeada por feedback dado pelos integrantes da equipe, de forma a buscar constantes melhorias na performance do projeto de extensão e no seu processo educacional, visando proporcionar a melhor experiência possível aos calouros no mundo da dança. As ações descritas vão ao encontro do que Carbonera e Carbonera (2008, p.44) afirmam:

(...) a Dança enquanto um processo educacional, não se resume simplesmente em aquisição de habilidades, mas sim, poderá estar contribuindo para o aprimoramento das habilidades básicas, dos padrões fundamentais do movimento, no desenvolvimento das potencialidades humanas e sua relação com o mundo.

A etapa de planejamento envolve a definição das atividades a serem realizadas e o estabelecimento dos resultados a serem alcançados. Nessa fase são definidos o plano de aula 
dos ritmos a serem ofertados para a turma semestral, as estratégias de divulgação das inscrições, o calendário de aulas e práticas de dança, o estabelecimento do esquema de capacitações da equipe pedagógica, além de serem discutidos os aspectos positivos do semestre anterior que devem ser perpetuados no semestre atual e os aspectos negativos que devem ser corrigidos.

Na segunda etapa, que se refere à organização, são alocadas as pessoas disponíveis para a realização das atividades planejadas. É feita a distribuição das tarefas entre os membros da equipe pedagógica, que inclui funções de designação dos responsáveis em ministrar tanto as aulas como as capacitações da equipe pedagógica, controle de frequência dos alunos, elaboração de artes para divulgação das atividades do Dançar Faz Bem, redação de textos, contato com o público, bem como a organização de eventos e demais atividades demandadas no decorrer do semestre.

Por fim, a etapa de realização das atividades propostas envolve a execução das ações elencadas nas etapas anteriores. Todas as atividades passam pela constante discussão de toda a equipe de forma a atingirem um consenso nas decisões demandadas para enfim serem colocadas em prática.

Ao final do semestre é realizada uma reunião com os alunos da turma vigente onde ocorre uma avaliação do desempenho das aulas ministradas, com a escuta do feedback dos alunos, cooperando, dessa forma, para o constante aperfeiçoamento da didática das aulas. Além da reunião com os alunos, também é realizada uma reunião da equipe pedagógica junto ao coordenador do Dançar Faz Bem, o professor Dr. Leandro Masuda, que orienta e acompanha as atividades realizadas pela equipe de professores e monitores.

\section{MATERIAIS E MÉTODOS}

O presente estudo, de caráter qualitativo, constitui-se como um relato de experiência de cunho descritivo baseado na vivência da autora no projeto de extensão em foco. Para a execução deste trabalho foi realizada uma pesquisa etnográfica, compreendida por Gil (2010) como o estudo de um grupo baseado em informações coletadas mediante trabalho de campo e pode se valer de técnicas de entrevista, observação participante, análise de documentos, fotografias e/ou filmagens.

Como suporte à observação participante, utilizou-se da metodologia de registro em 
diário de campo, que se trata de um recurso no qual é utilizado como ferramenta um caderno para anotações, comentários e reflexões de uso individual do pesquisador, conforme Falkembach (1987, apud GERHARDT; SILVEIRA, 2009).

As informações obtidas em diário de campo contaram com as observações registradas na fase de atuação na equipe pedagógica compreendida no período de fevereiro de 2017 a agosto de 2018, envolvendo a colaboração de 14 integrantes que passaram pela equipe e dos 212 alunos beneficiados pelo projeto de extensão nesse intervalo de tempo.

Recorreu-se igualmente às fotografias, filmagens e arquivos oficiais e particulares para a obtenção de dados referentes à fase de participação tanto como aluna do Dançar Faz Bem, ocorrida entre os anos de 2007 a 2009 e em 2016, quanto como membro atuante na equipe pedagógica.

O cenário do primeiro momento, enquanto discente, se deu na sala de artes do bloco da FACED (FIGURA 1) localizado no Centro de Humanidades I, Campus do Benfica, e o local da experiência do segundo momento, como membro integrante da equipe pedagógica, ocorre na sala de lutas do IEFES (FIGURA 2), situada no Campus do Pici.

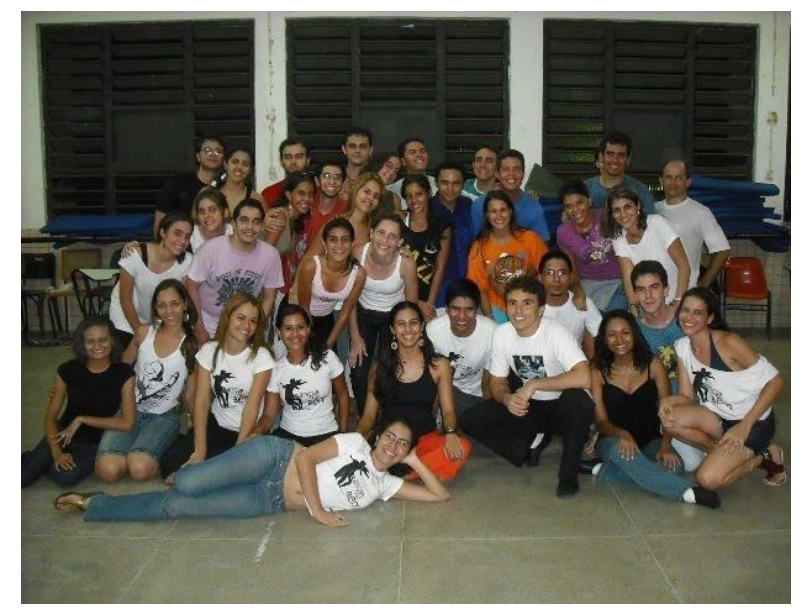

FIGURA 1 - Registro pós-aula da turma na FACED

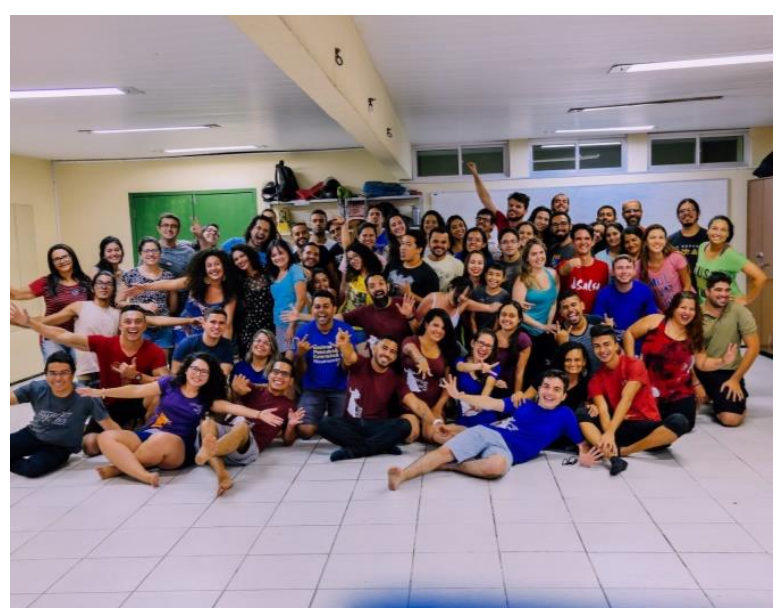

FIGURA 2 - Registro pós-aula da turma na sala de artes da sala de lutas do IEFES

A rotina da equipe pedagógica nos dias de aula consiste na seguinte metodologia:

a) Ensaio uma hora antes do início da aula;

b) Ministração das aulas, com duração de duas horas, que geralmente se estruturam da seguinte forma: alongamento/aquecimento; dinâmicas de grupo; revisão de conteúdo; intervalo; conteúdo novo e prática;

c) Reunião de feedback sobre a aula ministrada no dia. 
O desenvolvimento da passagem do conteúdo aos alunos é permeado pela constante atenção da equipe às dificuldades apresentadas pelo quadro discente e se dá pela inicial quebra dos passos propostos em movimentos menores, para que o aluno tenha noção de como a dinâmica dos passos se dão. Assim, além da fragmentação do passo ensinado, é realizada a repetição dos movimentos e é estimulada a constante troca de pares para que cada aluno tenha a experiência da diferença de comportamento de cada corpo diante do mesmo passo a ser executado.

Incentiva-se no decorrer da aula que alunos externem suas dúvidas e dificuldades perante a execução do conteúdo proposto e também que eles reproduzam continuamente para fixação do que foi repassado. O retorno dado por eles permite o conhecimento das suas percepções diante da experiência de extensão a qual eles estão vivenciando e posterior análise da didática mais adequada para que se chegue ao melhor resultado.

\section{RESULTADOS E DISCUSSÕES}

Na fase de análise dos dados identificou-se que no estágio de participação como aluna do Dançar Faz Bem, além do desenvolvimento das habilidades e consciência corporal que a dança propõe, foram estimuladas interações e relações sociais que permitiram superar a timidez e ansiedade, proporcionando, dessa forma bem-estar físico e emocional, corroborando com a afirmação de Nanni (2002), na qual a dança incita no ser humano a abertura para o desenvolvimento e aprimoramento das suas características sensoriais, emocionais, afetivas, uma vez que a dança, por ser uma arte conceitual, sensibiliza pela apreciação do belo, do estético e do moral.

Entendeu-se que a experiência de aprendizado na dança não se limita tão somente à reprodução de movimentos repassados em sala de aula, é um processo que envolve a consciência das limitações apresentadas pelo corpo, percepção da particularidade de estímulo do corpo de cada diferente parceiro e consequente reflexão de como responder aos diferentes estímulos. Além do desenvolvimento das habilidades corporais, as habilidades sociais também são trabalhadas, contribuindo para o aprimoramento das relações de amizade, autocontrole, expressividade, empatia, o que ajuda consequentemente na superação de possíveis dificuldades de relacionamento com o outro e consigo mesmo.

Quanto ao período de vivência como integrante da equipe pedagógica, verificou-se 
que o processo de ensino envolve ações que vão além do ato de simplesmente repassar os conteúdos propostos. Trata-se de uma dinâmica que requer constante atenção e empatia quanto ao que o aluno pode estar sentindo e vivenciando no momento da passagem dos movimentos. $\mathrm{O}$ frequente estímulo para que os alunos deem seu feedback a respeito da aula são importantes para a percepção do ponto de vista dos aprendizes, reconhecimento das suas dificuldades no aprendizado, reflexão e assimilação concreta do que foi ensinado.

A partir do relato dos alunos, é perceptível as contribuições do Dançar Faz Bem, tanto no campo de aprendizado da dança, como no desenvolvimento de vínculos sociais: "Através dele [Projeto Dançar Faz Bem], conheci pessoas maravilhosas, conquistei amizades e, principalmente, aprendi muita coisa! Agradeço a todos os professores que fazem parte do PDF[B] por nos motivar, ensinar e nos encantar pela dança. Vocês são referências para nós!" (ALUNA DFB 1). "Esse projeto é excelente, proporciona saúde e bem-estar pra todas as pessoas que buscam a autoestima e cultura da dança, é muito prazeroso dançar." (ALUNA DFB 2).

A realização das atividades as quais o Dançar Faz Bem se propõe são de grande significância para ambas as partes envolvidas, auxiliando tanto no desenvolvimento de competências educacionais da equipe pedagógica, como na aquisição dos conhecimentos e treinamento das habilidades sociais dos alunos. Entende-se, dessa forma, o papel da ação extensionista em questão para a sociedade.

\section{CONCLUSÃO}

A participação no projeto de extensão Dançar Faz Bem tem proporcionado experiências desafiadoras, no sentido de desenvolvimento de competências sociais e educacionais e igualmente enriquecedoras, contribuindo para a capacitação no campo docente, e, assim, permitindo compreender o papel do projeto com agente transformador de realidades, tanto de alunos, que se beneficiam com o bem-estar físico e mental proporcionado por essa atividade, como de professores, que encontram no DFB um campo rico para formação profissional no ensino da dança de salão.

As informações obtidas na pesquisa de campo demonstram que o Dançar Faz Bem tem alcançado a sua missão de disseminação do amor pela dança de salão de forma respeitosa, lúdica e cooperativa, proporcionando bem-estar e laços de amizade. As ações desse projeto 
demonstram a relevância do papel educador do profissional de dança e sua repercussão na vida do discente, que vai muito além da mera aquisição de conhecimentos, além do impacto do Dançar Faz Bem no cenário da dança de salão da cidade, cumprindo, dessa forma, o papel de transformação social inerente às ações extensionistas.

\section{REFERÊNCIAS}

CARBONERA, D.; CARBONERA, S. A. A importância da dança no contexto escolar. 2008. 61 f. Monografia (Pós-Graduação em Educação Física Escolar) - Faculdade Iguaçu, Instituto de Estudos Avançados e Pós-Graduação, Cascavel, 2008. Disponível em: < http://www.educadores.diaadia.pr.gov.br/arquivos/File/2010/artigos_teses/EDUCACAO_FISI CA/monografia/DANCA_ESCOLA.pdf>. Acesso em: 03 Ago. 2018.

EULÁliO, M. D. M. C.; NASCIMENTO, J. R.; ALBUQUERQUE, M. S. P. Didatizando o gênero relato de experiência no Ensino Fundamental: reflexão sobre reescrita textual. Revista Letras Raras, v. 2, n. 2, p. 52-70, 2013. Disponível em: < http://revistas.ufcg.edu.br/ch/index.php/RLR/article/viewFile/187/146>. Acesso em: 06 Ago. 2018.

GERHARDT, T. E.; SILVEIRA, D. T. Métodos de pesquisa. Porto Alegre: Editora da UFRGS, 2009.

GIL, A. C. Como elaborar projetos de pesquisa. São Paulo: Atlas, 2010. 5 ed.

MANUAL DO ALUNO DANÇAR FAZ BEM. Manual do Aluno Dançar Faz Bem 2018. Fortaleza, 2018.

NANNI, D. Dança educação - princípios, métodos e técnicas. 4. ed. Rio de Janeiro: Sprint, 2002.

PEREIRA, G. C. Dois pra lá, dois pra cá: a construção dos modelos de masculinidade e feminilidade na academia de dança de salão. 2011. 170 f. Dissertação (Pós-Graduação em Sociologia) - Departamento de Ciências Sociais, Universidade Federal do Ceará, Fortaleza, 2011. Disponível em: 〈http://www.repositorio.ufc.br/handle/riufc/6371〉. Acesso em: 03 Ago. 2018.

PROJETO DANÇAR FAZ BEM - UFC. O Projeto Dançar Faz Bem. Disponível em: < http://dancarfazbem.blogspot.com/p/quem-somos.html>. Acesso em: 04 Ago. 2018. UFCTV. Projeto 'Dançar faz Bem' oferece aulas de dança grátis. Produção: Mayra Pontes. Reportagem: Nut Pereira. Edição de texto: Rute de Alencar. Imagens: Álvaro Graça Jr. Edição de imagens: Roney Anderson. Janela de Libras: Secretaria de Acessibilidade UFC Inclui. Fortaleza: UFCTV, 2018. (4 min 18 s). Disponível em: $<$ http://www.ufc.br/noticias/noticias-ufctv/11737-projeto-dancar-faz-bem-oferece-aulas-dedanca-gratis $>$ 